\title{
Brief Analysis on Reconstruction Design of Small Studio
}

\author{
Zhang Xiaoyi \\ College of Architecture and Civil Engineering, Taiyuan University of Technology, Taiyuan City, Shanxi \\ Province, 030024
}

\begin{abstract}
: this paper aims to design and select acoustic finishing materials for processing and improving the materials of the ground, the walls and the ceiling according to the design bases and standards including Acceptable Noise Level for Technology Houses of Radio and Television Center, and aims to design the light shading and sound insulation windows, the soundproof door, the background screen and others, so as to prevent low frequency sound coloration in small houses.
\end{abstract}

KEYWORD: studio; materials

\section{INTRODUCTION}

In order to realize the modernized education and satisfy the demand for preparing audio-visual education films, we established a small studio in the campus, which is dedicated to recording of linguistic broadcasts including news and special topics. Nevertheless, we must comprehensively evaluate the acoustic finishing design of a studio from the aspects of acoustic design, construction, testing acceptance and use, so as to determine whether or not it is perfect.

\section{DESIGN REQUIREMENTS AND CONDITIONS OF STUDIO}

As there was no reasonable space reserved for a studio in the civil design during construction, the established studio was reconstructed from an office on the third floor of the main building in the campus. As for a studio, the indoor tone quality determines the tone quality of all audio video recording products, so the acoustic finishing design of the studio is extremely important.

a) The studio is mainly used for TV camera shooting and sound recording, lays in the direction of north-south, and is located at the north.

b) The original tile floor and double-glazed windows are kept unchanged, and a heating radiator against the window protrudes out of the wall surface for $0.18 \mathrm{~m}$. c) Based on requirements for the studio, the indoor noise control should be satisfactory, the reverberation time and frequency characteristic should be proper, and the indoor sound field distribution should be uniform.

d) As for the surroundings of the studio, a playground lies outside the north window, a corridor is outside the door, the studio is on the third floor with corresponding houses located on the second and fourth floors, the house on the fourth floor does not affect the recording in the studio, and daily activities are conducted in the house on the second floor sometimes.

e) The north wall (external wall) is $490 \mathrm{~mm}$ thick with the inner side plastered. The south wall is $370 \mathrm{~mm}$ thick, and the partitioning walls on the two sides are $240 \mathrm{~mm}$ thick, with both sides plastered.

f) In order to prevent low-frequency sound coloration in the small house, the acoustic design of the floor, the walls and the ceiling, the light shading and sound insulation of the windows, the soundproof door, the background screen and the like are all taken into consideration. The wall-mounted air conditioner should be mounted at proper place and not used during recording; however, sound transmission of the pipelines of the air conditioner needs to be considered.

g) The materials and equipment must have the required functions and satisfy requirements for environment protection, fire prevention and market availability.

h) The original house is $5.487 * 3.038 * 3.295(\mathrm{~m})$ 
in dimension, $16.5 \mathrm{~m}^{2}$ in floor area and $54.45 \mathrm{~m}^{3}$ in volume. The detailed parameters are shown in the Figure 1 and the Figure 2.
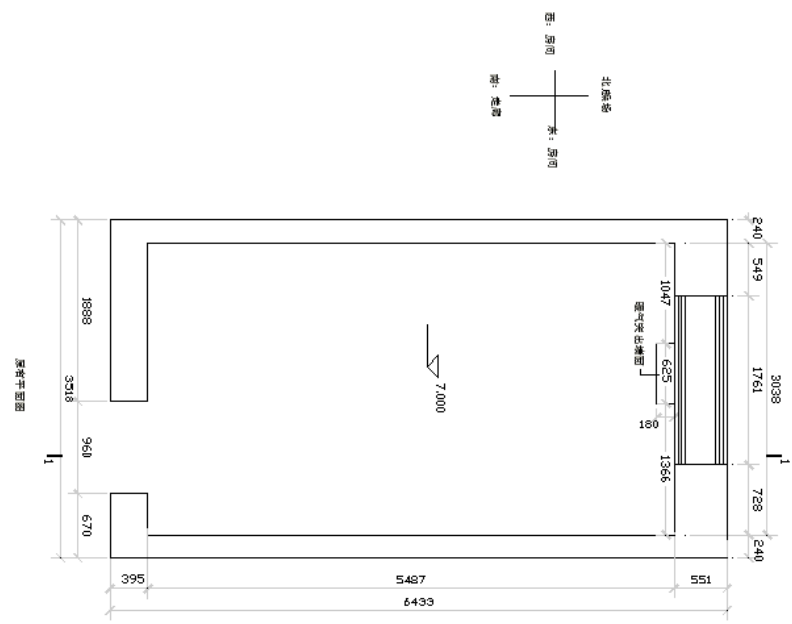

Figure 1. Plan of Original House

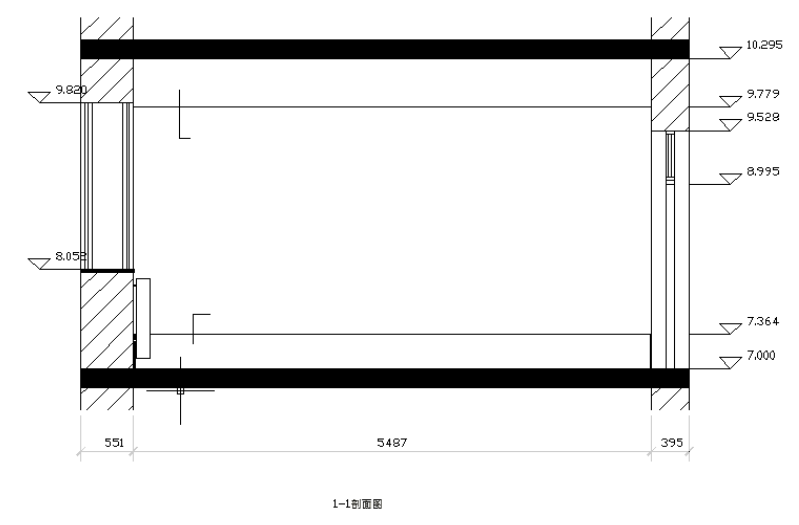

Figure 2. Profile of Original House

\section{ACOUSTIC DESIGN OF STUDIO}

\subsection{Reverberation time}

Up to now, there has not a mandatory unified requirement on the reverberation time of the studio yet. At present, the indoor sound absorption layer with short-period reverberation design has an extraordinary sound absorption effect, thereby being widely adopted. The reconstructed studio has a small size, is mainly used for recording broadcasting programs functionally, and lays the emphasis on the definition of the tone quality, with the reverberation time controlled at 0.3 second and the frequency characteristic preferably approaching to straightness. In acoustic quality design for linguistic studio, $T_{60}$ is commonly used for representing the frequency characteristic of the reverberation time of the studio, and corresponds to six frequencies including $125 \mathrm{~Hz}$, $250 \mathrm{~Hz}, 500 \mathrm{~Hz}, 1000 \mathrm{~Hz}, 2000 \mathrm{~Hz}$ and $4000 \mathrm{~Hz}$. Therefore, during design and selection of acoustic finishing materials, the combined structure of multiple materials instead of only one single sound absorption structure is adopted for providing a better frequency response range. The reverberation time is generally computed as per the following formula:

where $\mathrm{T}_{60}$ refers to the reverberation time of the studio (s); V refers to the volume of the studio $\left(\mathrm{m}^{3}\right)$; $S$ refers to the total indoor floor area of the studio $\left(\mathrm{m}^{2}\right) ; \bar{\alpha}$ refers to the average sound absorption coefficient in unit area; $m$ refers to the acoustic absorption coefficient in air; $S_{i}$ refers to the area of the $i^{\text {th }}$ kind of sound absorption material $\left(\mathrm{m}^{2}\right) ; a_{i}$ refers to the acoustic absorption coefficient of the $i^{\text {th }}$ kind of sound absorption material.

Apply the sound absorption coefficient and quantities of the materials into the Erying Formula, perform checking computations and tests repeatedly, and finally work out multiple schemes by comparing and selecting various materials in different combinations.

\subsection{Selection and design of sound absorption and insulation materials}

We insulate the sound from the sound source and adopt sound absorption measure for transmission of the sound, so that the background noise and the noise radiation inside the studio can satisfy the standard requirement. The parts need to be reworked mainly include the floor, the walls, the suspended ceiling, the sound lock, the door and windows, the air conditioning equipment, other equipment pipelines and so on. By considering and analyzing the overall conditions of the project, we obtain the specific structures as follows.

a) The flame-retardant acoustic transmission fabric sound absorption structure is adopted for the wall surfaces so as to ensure the sound absorption capability of the studio (refer to Fig.3); and further, the sound absorption proportion of the structure is 1 to 2 , that is to say, one third of the area is a $100 \mathrm{~mm}$-thick cavity covered with fivelayer plywoods and finish coats. Two third of the area is a $50 \mathrm{~mm}$-thick cavity finished with the sound transmission fire-retardant cloth, internally filled with a $50 \mathrm{~mm}$-thick blanket of extra-fine glass wool, and covered with a layer of glass wool cloth. The preserved cavity layers of the sound absorption walls shall be constructed according to the projected depth strictly, so as to avoid influences on low-frequency sound absorption capability. 


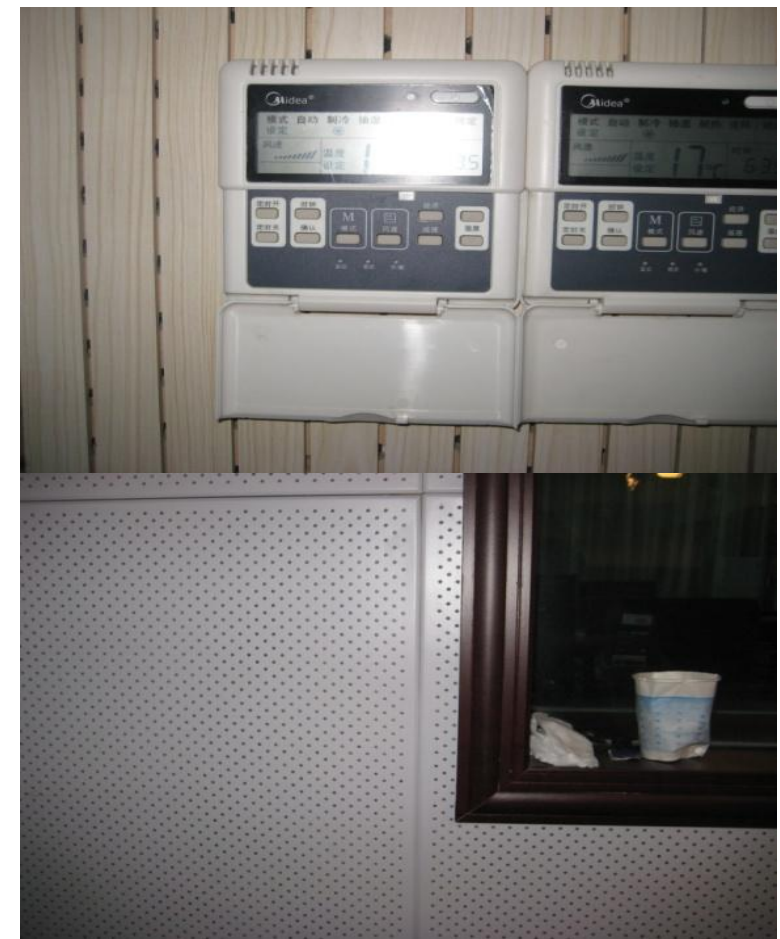

Figure 3. Wall Surface Treatment

b) The original tile floor is paved with flameretardant carpet and the plastic floor, with total thickness of $8 \mathrm{~mm}$ (shown in Fig. 4). Such elastic surface layer and elastic cushion layer are mainly adopted for insulating the floor collision sound (such as noise from the downstair room and footstep), can also absorb the low frequency effectively, are convenient to clean, and are not easy to wear.

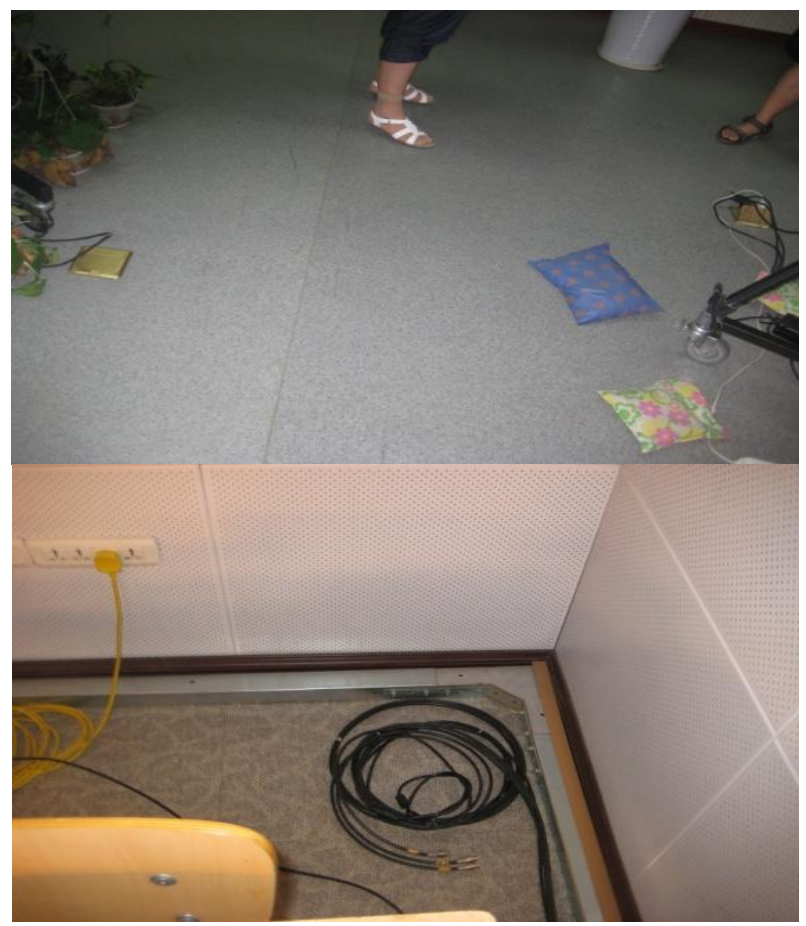

Figure 4. Floor Pavement

c) The ceiling adopts aluminum gratings, and the strong sound absorption structure of sound absorption glass wool is arranged on the ceiling (as shown in Figure 5), so that the indoor reverberation time can be efficiently controlled and the sound can be prevented from transmitting downwards.

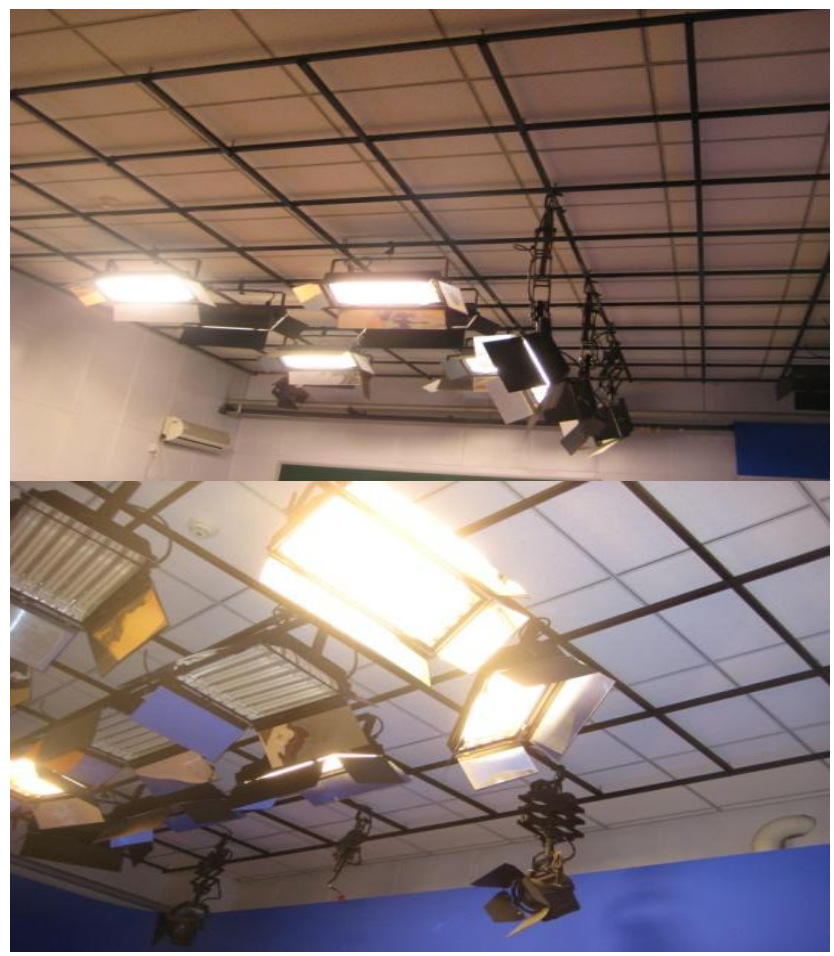

Figure 5. Ceiling Reconstruction

d) As for the door and the windows, the sound insulation capability of the common wood door is generally 15 to $18 \mathrm{~dB}$, which is far away from the $50 \mathrm{~dB}$ requirement for the background noise, so the specialized soundproof door shall be designed. After thorough consideration, we adopt the double-layer light soundproof door which is made of materials including double-layer plywoods (12 $\mathrm{mm}$ thick), steel plates (1 $\mathrm{mm}$ thick), $48 \mathrm{~K}$ soundproof cotton (100 mm thick), and decorative aluminium-plastic panels. The cavity inside the double-layer soundproof door is small, and a muffler pipe is arranged in the cavity for exhausting air indoors, otherwise, the door is difficult to close due to the counterforce of air compression. The gaps in the soundproof door and windows are sealed by sealing rubber strips, so that the outdoor ambient sound can be insulated. The soundproof door adopts specialized soundproof lock, so as to avoid gaps and further ensure the soundproof effect. Based on the practical measurements, the sound insulation of each single door leaf is $39 \mathrm{~dB}$, and the sound insulation of both door leaves in closed state achieves $52 \mathrm{~dB}$. The specialized soundproof inspection window (double layers of glass, with spacing not less than $10 \mathrm{~cm}$ ) is adopted between the control room and the studio for sound insulation, and the sound insulation capability is not less than $50 \mathrm{~dB}$. 
e) As for the pipelines and the air conditioner, gaps are not allowed at the wall entrances of the equipment pipelines in the studio, and expanding soundproof materials are used for blocking the gaps, so that the best noise insulation effect can be achieved. The vibrating noise of the air conditioning equipment needs to be insulated mainly, the vibration preventive elastic connection is adopted for the wall penetrating part of the air duct suspender and the air duct, a noise reduction net is arranged on the air conditioner external unit, and silencers and soundproof sleeves are additionally mounted on the air ducts. All soundproof structures mentioned above are crucial; and the unsatisfactory structures not only cause acoustic pollution to the surrounding environment, but also affect the reverberation effect in the studio.

\section{CONCLUSION}

In this paper, a series of experimental measurements as well as procedures of analysis, theoretical calculation and design are conducted on basis of the specific conditions of the studio, as a result, the feasible reconstruction design scheme is figured out. The studio is functionally used for recording linguistic programs, which requires high speech articulation and high speech intelligibility regarding the acoustics. For this purpose, the studio should have satisfactory reverberation time and frequency characteristic, low background noise label and favorable sound field diffusance, so as to avoid acoustic defects. By achieving the above design requirements, the studio will have a good tone quality effect.

\section{REFERENCES}

[1] Liu Xiaotu. Building Physics (3rd edition). Beijing: China Architecture \& Building Press. 2010

[2] Acceptable Noise Level for Technology Houses of Radio and Television Center (GYJ42_-89)

[3] Fire Protection Standard for Radio and TV Engineering Construction Design (GYJ33 - 88)

[4] Requirements on Ambient of Technology Houses of Broadcast and TV Center (GYJ43-90)

[5] Reverberation Time and Frequency Characteristic of Studio (GYJ26-86) 